\title{
Efficacy and safety of tracheobronchoplasty after induction therapy for locally advanced lung cancer
}

\author{
Mitsunori Ohta, MD \\ Noriyoshi Sawabata, MD $^{\mathrm{b}}$ \\ Hajime Maeda, MD ${ }^{\text {b }}$ \\ Hikaru Matsuda, $\mathrm{MD}^{\mathrm{a}}$
}

From the Department of General Thoracic Surgery, Osaka University, Graduate School of Medicine, ${ }^{\mathrm{a}}$ and the Division of Surgery, Toneyama National Hospital, ${ }^{\text {b }}$ Osaka, Japan

Received for publication Feb 12, 2002; revisions requested March 11, 2002; revisions received April 3, 2002; accepted for publication May 21, 2002.

Address for reprints: Mitsunori Ohta, MD, Department of General Thoracic Surgery, Osaka University Graduate School of Medicine, E1 2-2, Yamadaoka, Suita, Osaka, 565-0871, Japan (E-mail: ohta@ surg1.med. osaka-u.ac.jp).

J Thorac Cardiovasc Surg 2003;125:96-100

Copyright () 2003 by The American Association for Thoracic Surgery

$0022-5223 / 2003 \$ 30.00+0$

doi: $10.1067 / \mathrm{mtc} .2003 .91$
Objectives: Patients receiving induction therapy may have increased risk of morbidity and mortality after surgery. We retrospectively evaluated the influence of preoperative treatment in patients who underwent sleeve resection for lung cancer.

Methods: A series of 48 consecutive patients who underwent sleeve resection with a telescoping anastomosis was retrospectively analyzed. A sleeve lobectomy and pneumonectomy were performed in 41 and 7 patients, respectively. Twenty patients received preoperative induction therapy; of them, 16 received induction chemoradiotherapy and 4 received only chemotherapy. Twenty-eight patients underwent the procedure without adjuvant therapy.

Results: The telescopic procedure was performed by placing sutures around the proximal and distal portions of the bronchial cartilage without wrapping the anastomosis. Among the 20 patients who received induction therapy, pulmonary angioplasty was performed in 5 and chest wall resection was performed in 3. Seven of these 20 patients $(35 \%)$ had postoperative complications. Among the 28 patients without preoperative adjuvant therapy, pulmonary angioplasty was performed in 3 , diaphragmatic resection was performed in 1 , and chest wall resection was performed in 1 . Three of these 28 patients $(11 \%)$ had postoperative complications. Complications relating to the anastomosis occurred in 1 patient (5.0\%) who received induction therapy; however, no operative deaths occurred. Bronchoscopic examinations demonstrated that mucosal healing was prolonged in patients who underwent induction therapy.

Conclusion: Induction therapy did not significantly affect morbidity or mortality among patients who underwent sleeve resection.

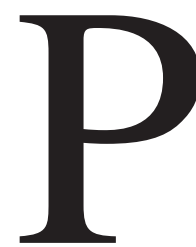

reoperative induction chemoradiotherapy is considered to improve survival; however, the treatment may also induce related complications. ${ }^{1-3}$ Various techniques involving vital tissues have been used to lessen the usually high incidence of postoperative complications among patients undergoing bronchial sleeve resection after induction therapy. ${ }^{4-6}$ We have had some success with a telescoping anastomosis for primary sleeve resection without any anastomosis-related complications, so in 1993 we also began to use a telescoping method for bronchoplasty procedures after induction therapy. A recent study found that preoperative chemotherapy did not significantly affect morbidity or mortality after surgery, ${ }^{7}$ and our experience with sleeve resections after induction therapy confirmed those results. We examined the influence of induction therapy on sleeve resection surgical results by retrospectively comparing patients who received induction therapy with those who did not.

\section{Patients and Methods}

We treated 484 patients with lung cancer from 1993 to 2001, of whom 48 (9.9\%) underwent circumferential resection of the bronchus or carina with pulmonary resection. Forty-one of 
TABLE 1. Patient characteristics

\begin{tabular}{|c|c|c|c|}
\hline & $\begin{array}{c}\text { Surgery after } \\
\text { induction therapy }\end{array}$ & $\begin{array}{l}\text { Surgery } \\
\text { alone }\end{array}$ & $P$ value \\
\hline No. of patients & 20 & 28 & \\
\hline Age $(y$, mean $\pm S D)$ & $58 \pm 10$ & $62 \pm 10$ & .18 \\
\hline Sex (male/female ratio) & $14: 6$ & $21: 7$ & .95 \\
\hline \multicolumn{4}{|l|}{ Histologic type (No.) } \\
\hline Squamous cell carcinoma & 13 & 17 & \\
\hline Adenocarcinoma & 7 & 6 & \\
\hline Other & 0 & 5 & .11 \\
\hline \multicolumn{4}{|l|}{ Clinical stage before treatment (No.) } \\
\hline I & 0 & 6 & \\
\hline II & 0 & 15 & \\
\hline IIIA & 12 & 2 & \\
\hline IIIB & 8 & 5 & $<.0001$ \\
\hline \multicolumn{4}{|l|}{ Type of operation (No.) } \\
\hline Sleeve pneumonectomy & 3 & 4 & \\
\hline Sleeve lobectomy & 16 & 18 & \\
\hline Sleeve bilobectomy & 1 & 6 & .28 \\
\hline \multicolumn{4}{|l|}{ Combined operation } \\
\hline$(-)$ & 12 & 24 & \\
\hline $\begin{array}{l}\text { Angioplasty of pulmonary artery, } \\
\text { pulmonary vein, or superior } \\
\text { vena cava }\end{array}$ & 5 & 3 & \\
\hline Chest wall resection & 3 & 1 & .12 \\
\hline
\end{tabular}

those patients underwent sleeve lobectomy and 7 underwent sleeve pneumonectomy (Table 1). There were 35 male and 13 female patients ranging in age from 38 to 84 years (mean 59 years). Histologic examinations revealed squamous cell carcinoma in 30 patients, adenocarcinoma in 13, adenosquamous cell carcinoma in 1 , typical carcinoid in 3 , and adenoid cystic carcinoma in 1 . In each case we elected to perform a telescoping anastomosis for sleeve resection. The preoperative conditions, findings, and results from these patients were examined in a retrospective analysis.

\section{Evaluation of Stage and Treatment Strategy}

The patients routinely underwent computed tomographic examination of the chest and upper abdomen, magnetic resonance imaging of the head, bone scans, lung function tests, and fiberoptic bronchoscopy. In those with insufficient lung function, lung perfusion scans were also performed. Patients with stages IIIA and IIIB disease received induction therapies before the operation. Mediastinal lymphadenopathy was diagnosed by chest computed tomography without histologic confirmation, whereas supraclavicular lymphadenopathy and malignant pleural effusion were diagnosed by pathologic examination. Patients with malignant pleural effusion, contralateral mediastinal lymphadenopathy, or pulmonary metastasis were excluded. However, 1 patient who had a right-sided Pancoast tumor with ipsilateral supraclavicular lymph node metastasis (N3 disease) was included. Before induction therapy, there were 14 patients with N2 disease, 1 with N3 disease, 9 with T3 disease, and 7 with T4 disease; thus 12 patients had stage IIIA disease and 8 had stage IIIB disease.

Sixteen patients received cisplatin-based combination chemotherapy with concurrent radiation therapy to the primary tumor and mediastinum before the operation, and another 4 patients received only chemotherapy. Chemotherapy treatments consisted of four different combinations: cisplatin and vindesine were administered to 11 patients; cisplatin, vindesine, and mitomycin were administered to 4 patients; cisplatin and docetaxel were administered to 4 patients; and low-dose carboplatin as an enhancer of radiation was administered to 1 patient. All patients, except for 2 in the cisplatin and vindesine therapy group, received two cycles of chemotherapy. Radiation therapy with an average of 42 Gy (range 30-50 Gy) was initiated concurrently at $2 \mathrm{~Gy} /($ fraction $\cdot \mathrm{d}$ ) on the first day of the initial cycle of chemotherapy. Patients receiving induction therapy underwent surgical resection of the residual tumor at the primary site and vestiges on neighboring organs within 4 weeks after the last treatment.

Sleeve lobectomy was achieved with an anteroaxillar thoracotomy in principle. When a radical pretracheal or paratracheal lymphadenectomy was required in a left-sided operation, a trapdoor thoracotomy (half median sternotomy with fourth intercostal space thoracotomy) was performed. A standard posterolateral thoracotomy was used for right sleeve pneumonectomy and a bilateral anteroaxillar thoracotomy was performed for left sleeve pneumonectomy to achieve adequate dissection of the mediastinal lymph nodes.

\section{Operative Procedure}

Resection of the subcarinal, paratracheal, and hilar peribronchial lymph nodes was carried out before bronchial incision. For patients with a Pancoast tumor, a supraclavicular lymphadenectomy was also performed. The anastomosis was constructed of a single interrupted whole-layer suture with 4-0 PDS-II or Maxon sutures for sleeve lobectomy and 3-0 PDS-II (Ethicon, Inc, Somerville, NJ) or Maxon (United States Surgical Corp, Norwalk, Conn) 

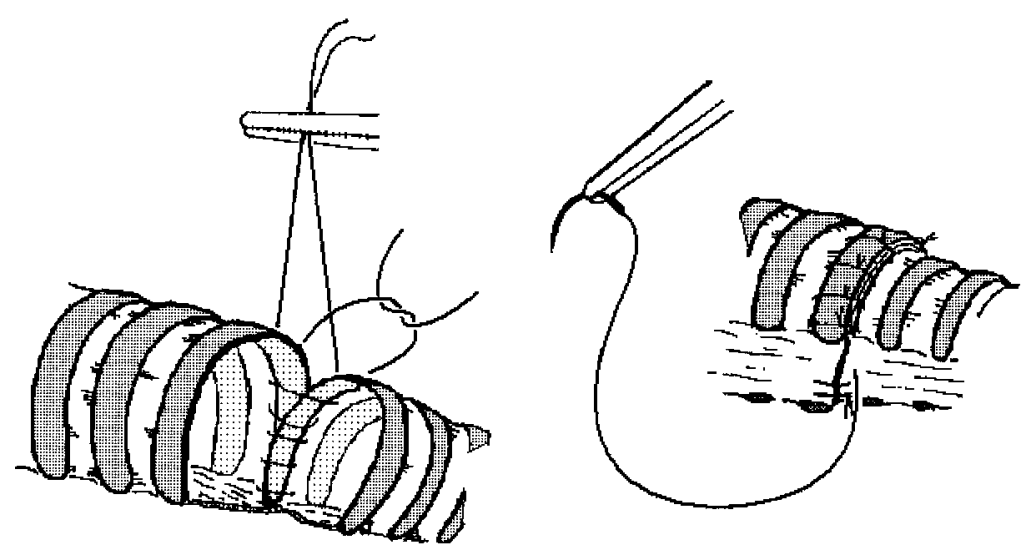

Figure 1. Telescoping bronchial anastomosis procedure. Anastomosis is initiated from mediastinal side of cartilage with 4-0 PDS-II sutures. Placement of sutures around cartilage is critical in achieving good telescoping effect. Cartilage sutures are tied and membranous portion is sutured. Distal bronchus is then inserted into proximal bronchus at depth equal to circumference of cartilage.

sutures for sleeve pneumonectomy. After two sutures were placed around the cartilages at the mediastinal end, the first suture was tied in an extraluminal fashion. The subsequent suture was then placed before the second suture was knotted (Figure 1). The telescoping effect was achieved by placing the stitches around the proximal and distal cartilage. The anastomosis of the membranous portion was performed with either an interrupted or a continuous suture technique. When the anastomosis was complete, the bronchus was telescoped by a depth of one circumference of cartilage. Wrapping of the anastomosis was not performed; however, a pedicled pericardial fat pad was used for coverage of the vascular anastomosis in cases of combined vascular sleeve resection. The anastomosis was checked for leaks with a pressure of $30 \mathrm{~cm} \mathrm{H}_{2} \mathrm{O}$ for 3 seconds.

\section{Types of Operations}

Twenty patients received preoperative induction therapy, of whom 17 underwent sleeve lobectomy and 3 underwent sleeve pneumonectomy ( 2 right and 1 left). Five of these 20 patients underwent lobar pulmonary angioplasty and 3 underwent chest wall resection. In addition, 28 patients underwent primary sleeve resection without adjuvant therapy, of whom 24 underwent sleeve lobectomy and 4 underwent right-sided sleeve pneumonectomy. Two of these patients underwent angioplasty of a pulmonary artery or vein, 1 underwent resection of the diaphragm, and 1 underwent angioplasty and chest wall resection.

Fiberoptic Bronchoscopic Examinations after Surgery At the end of the operation, the anastomosis was inspected with a bronchoscope. Bronchoscopic examination was repeated 1 and 2 weeks later, or every week if postoperative complications or prolonged mucosal healing at the anastomotic site was observed.

\section{Statistical Analysis}

Differences between two groups were tested for significance by the $\chi^{2}$ test for categoric variables and the Student $t$ test for continuous variables. Survival was estimated by the Kaplan-Meier method.

\section{Results}

Clinical factors of the patients who underwent sleeve resection after induction therapy were similar to those of patients without induction therapy except for clinical stage (Table 1).

\section{Complications in Patients Who Received Induction Therapy}

A total of 7 patients who received induction therapy (35\%) had postoperative complications (Table 2). Two patients with poor pulmonary function required mechanical ventilation with tracheotomy, and 1 patient acquired pneumonitis from methicillin-resistant Staphylococcus aureus and received medical treatment under mechanical ventilation. Further complications included 1 patient who underwent dissection of a right-sided Pancoast tumor and had recurrent nerve and ulnar nerve palsy develop, 2 patients who had pleural empyema develop, and 1 patient in whom stricture of the anastomosis, which developed after infection with Pseudomonas cepacia at the anastomosis site, was successfully treated with balloon dilatation after the infection had resolved. Bronchoscopic examination frequently revealed white, necrotic mucosa along the cartilage of the distal bronchial end, which persisted for approximately 3 weeks.

\section{Complications in Patients Without Induction Therapy}

Three patients who did not receive induction therapy (11\%) had postoperative complications develop (Table 2). One patient required mechanical ventilation for 2 days after surgery because of laryngeal edema, 1 acquired pleural empyema, and 1 acquired chylothorax.

The rates of morbidity were 35\% ( $\mathrm{n}=7 / 20)$ among patients who received induction therapy and $11 \%(\mathrm{n}=$ 3/28) among those who did not. An anastomosis-related 
complication was observed in 1 patient who received induction chemoradiotherapy. No postoperative deaths occurred, and all patients were discharged in an ambulatory condition.

\section{Survival and Cause of Death}

Patients were followed up from 4 to 93 months (mean \pm SD $25.4 \pm 19.6$ months). For the analysis of survival, 3 patients with carcinoid lung cancer and 1 with adenoid-cystic carcinoma were excluded, because the prognoses for these types of lung cancer are much better than for other types of non-small cell lung cancer. Four patients who received induction therapy died between postoperative months 16 and 53. One of these had local recurrence in the mediastinum 13 months after the operation, 2 had tumor recurrence at a distant site, and 1 died of a non-tumor-related cause. Six who did not receive induction therapy died between postoperative months 5 and 32. One of these patients had local recurrence in the residual lung 30 months after surgery, 5 had tumor recurrence at a distant site, and 1 died of pneumonitis. The median survivals were 19.3 months for all 44 patients, 23 months for the 20 patients who received induction therapy, and 17.9 months for the 24 who did not receive induction therapy.

\section{Discussion}

Chemotherapy or chemoradiotherapy followed by surgery is considered to be an effective treatment modality for locally advanced lung cancer in stage IIIA or IIIB. However, lung resections after induction therapy are technically demanding, and between $27 \%$ and $56 \%$ of the patients with an infiltrative centrally located tumor require pneumonectomy. ${ }^{5,8}$ Rendina and colleagues ${ }^{4}$ showed that a bronchoplasty with vascular reconstruction could reduce the rate of pneumonectomy to $7.3 \%$ and considered bronchovascular reconstructive surgery to be an effective alternative to a pneumonectomy after induction chemotherapy. In our series of patients, induction therapy was indicated for those with stages IIIA and IIIB disease. When the patients had a resectable T4 tumor, such as a carinal invasion without N2 or N3 disease, a primary operation was performed. Overall, we performed surgery on 86 patients after induction therapy, $20(23 \%)$ of whom underwent sleeve resection. The choice of sleeve resection for patients after induction therapy was based on curative intent and the desire to preserve as much functional lung volume as possible. The 28 patients who did not receive induction therapy underwent operations with the same intent.

Induction therapy, particularly irradiation, may cause serious anastomotic complications. ${ }^{9,10}$ According to several reports, radiotherapy before sleeve resection should be avoided $^{9,11}$ or limited to $30 \mathrm{~Gy} .{ }^{12}$ When sufficient irradiation dosages are used, the use of omentum to enhance the blood supply is recommended. ${ }^{6}$ When preoperative chemo-
TABLE 2. Postoperative results

\begin{tabular}{|c|c|c|c|}
\hline & $\begin{array}{l}\text { Surgery after } \\
\text { induction therapy }\end{array}$ & $\begin{array}{l}\text { Surgery } \\
\text { alone }\end{array}$ & $P$ value \\
\hline No. of patients & 20 & 28 & \\
\hline \multicolumn{4}{|l|}{ Complications (No.) } \\
\hline $\begin{array}{l}\text { Reintubation or } \\
\text { tracheotomy for } \\
\text { respiratory failure }\end{array}$ & 2 & 1 & \\
\hline Pneumonia & 1 & 0 & \\
\hline Empyema & 2 & 1 & \\
\hline Stricture of anastomosis & 1 & 0 & \\
\hline Other & 1 & 1 & \\
\hline Total & 7 & 3 & .092 \\
\hline Pathologic stage* (No.) & & & .2 \\
\hline I & 5 & 7 & \\
\hline II & 2 & 9 & \\
\hline IIIA & 9 & 6 & \\
\hline IIIB & 4 & 6 & \\
\hline Survivalt & $\mathrm{n}=20$ & $\mathrm{n}=24$ & \\
\hline Median survival (mo) & 23 & 17.9 & .58 \\
\hline Death from cancer (No.) & 3 & 5 & \\
\hline $\begin{array}{l}\text { Death other than from } \\
\text { cancer (No.) }\end{array}$ & 1 & 1 & .97 \\
\hline
\end{tabular}

*Pathologic stage was based on pathologic examinations of resected specimen and operative findings.

†Median survival was calculated for all patients without carcinoid and adenocystic carcinoma.

therapy is performed, bronchial sutures should be protected by well-vascularized tissue, such as an intercostal muscle flap. ${ }^{4}$ In the patients in this retrospective study, wrapping to prevent early complications may have been unnecessary, as shown in a previous experimental report, ${ }^{13}$ even for patients who received induction therapy. Moreover, a telescopic procedure without wrapping has frequently been applied to single-lung transplantation with good results. ${ }^{14} \mathrm{We}$ believe that for a successful telescope it is crucial to achieve a depth equal to one cartilage and to cover the full circumference of the bronchus. A telescoping anastomosis seems to be a simple and reliable technique, especially for patients receiving induction therapy.

The results from our series of 48 consecutive cases indicate that bronchoplasty can be performed fairly safely in patients undergoing induction therapy, including irradiation. Morbidity of patients undergoing airway reconstruction with wrapping of a vascularized tissue flap after induction chemotherapy has been reported to be $11 \%(\mathrm{n}=3 / 27),{ }^{4}$ and the rate increased to $36 \%(n=8 / 22)$ when concomitant with radiotherapy. ${ }^{6}$ Our postoperative morbidity rate of $35 \%$ among patients who received induction therapy lies within that range, and the rate of anastomotic stricture was only $5.0 \%(\mathrm{n}=1 / 20)$. Further, the morbidity rate among the 28 patients who underwent a sleeve resection without induction therapy was $11 \%$, and no anastomosis-related complications were observed in that group. 
Our patients had no local recurrences in the airway; however, $2(4.2 \%)$ had intrathoracic relapses of disease and 7 had relapses at a distant site. The median survival was 23 months among patients with induction therapy and 18 months among those without it. Although it is not appropriate to compare median survivals between the patients who received induction therapy and those who did not because they had different stages of disease, the median survival findings for our patients who received induction therapy compared favorably with those in other major series. ${ }^{2,5,8}$ Our study population was not large enough to detect small differences in surgical morbidity or survival, so the influence of induction therapy must be carefully evaluated. Nevertheless, the surgical outcomes relating to bronchial anastomosis were similar to the best results reported elsewhere. ${ }^{4,12}$

In summary, the results of our retrospective study suggest that morbidity and mortality after sleeve resection were not significantly affected by preoperative induction therapy when a meticulous technique was used and proper patient selection was performed.

\section{References}

1. Choi NC, Carey RW, Daly W, Mathisen D, Wain J, Wright C, et al. Potential impact on survival of improved tumor downstaging and resection rate by preoperative twice-daily radiation and concurrent chemotherapy in stage IIIA non-small-cell lung cancer. J Clin Oncol. 1997; 15:712-22.

2. Albain KS, Rusch VW, Crowly JJ, Rice TW, Turrisi AT, Weick JK, et al. Concurrent cisplatin/etoposide plus chest radiotherapy followed by surgery for stage IIIA (N2) and IIIB non-small-cell lung cancer: mature results of Southwest Oncology Group phase II study 8805. J Clin Oncol. 1995;13:1880-92.
3. Roberts JR, Eustis C, Devore R, Carbone D, Choy H, Johnson D. Induction chemotherapy increases perioperative complication in patients undergoing resection for non-small cell lung cancer. Ann Thorac Surg. 2001;72:885-8.

4. Rendina ER, Venuta F, De Giacomo T, Flaishman I, Fazi P, Ricci C, et al. Safety and efficacy of bronchovascular reconstruction after induction chemotherapy for lung cancer. J Thorac Cardiovasc Surg. 1997;114:830-7.

5. Rosell R, Gomez-Codina J, Camps C, Maestre J, Padille J, Canto A, et al. Randomized trial comparing preoperative chemotherapy plus surgery with surgery alone in patients with non-small-cell lung cancer. N Engl J Med. 1994;330:153-8.

6. Muehrcke DD, Grillo HC, Mathisen DJ. Reconstructive airway operation after irradiation. Ann Thorac Surg. 1995;59:14-8.

7. Siegenthaler MP, Pisters KM, Merriman KW, Roth JA, Swisher SG, Walsh GL, et al. Preoperative chemotherapy for lung cancer dose not increase surgical morbidity. Ann Thorac Surg. 2001;71:1105-12.

8. Sugarbaker DJ, Herndon J, Kohman LJ, Krasna MJ, Green MR. Results of cancer and leukemia group B protocol 8935: a multiinstitutional phase II trimodality trial for stage IIIA (N2) non-small-cell lung cancer. Cancer and Leukemia Group B Thoracic Surgery Group. J Thorac Cardiovasc Surg. 1995;109:473-85.

9. Dartevelle PG, Khalife J, Chapelier A, Marzelle J, Navajas M, Levasseur $\mathrm{P}$, et al. Tracheal sleeve pneumonectomy for bronchogenic carcinoma: report of 55 cases. Ann Thorac Surg. 1988;46:68-72.

10. Yamamoto R, Tada H, Kishi A, Tojo T. Effects of preoperative chemotherapy and radiation therapy on human bronchial blood flow. J Thorac Cardiovasc Surg. 2000;119:939-45.

11. Deslauriers J, Beaulieu M, McClish A. Tracheal sleeve pneumonectomy. In: Shields TW, editor. General thoracic surgery. 3rd ed. Philadelphia: Lea and Febiger; 1989. p. 382-7.

12. Roviaro G, Varoli F, Romanelli A, Vergani C, Maciocco M. Complications of tracheal sleeve pneumonectomy: personal experience and overview of the literature. J Thorac Cardiovasc Surg. 2001;121:23440.

13. LoCicero J 3rd, Massad M, Oba J, Bresticker M, Greene R. Short-term and long-term results of experimental wrapping techniques for bronchial anastomosis. J Thorac Cardiovasc Surg. 1992;103:763-6.

14. Calhoon JH, Grover FL, Gibbons WJ, Bryan CL, Levine SM, Bailey SR, et al. Single lung transplantation: alternative indications and technique. J Thorac Cardiovasc Surg. 1991;101:816-25.

\begin{abstract}
Online-www.aats.org
Now you can get The Journal of Thoracic and Cardiovascular Surgery online. The Journal online brings you faster delivery time, easy searching of current and back issues, links to PubMed, AATS, WTSA, and other important sites, and more. Visit the Journal online today.
\end{abstract}

\title{
Receive tables of contents by e-mail
}

To receive the tables of contents by e-mail, sign up through our Web site at http://www.mosby.com/jtcvs

Choose E-mail Notification

Simply type your e-mail address in the box and click the Subscribe button.

Alternatively, you may send an e-mail message to majordomo@mosby.com.

Leave the subject line blank and type the following as the body of your message: subscribe jtcvs_toc

You will receive an e-mail to confirm that you have been added to the mailing list.

Note that TOC e-mails will be sent out when a new issue is posted to the Web site. 